Research Article

\title{
Structural Characteristics Analysis of Overlying Rocks and Prevention Measures with a Long-Wall Face Passing Across Abandoned Roadways: A Case Study
}

\author{
Zeng-Qiang Yang $\mathbb{D},{ }^{1}$ Chang Liu $\left(\mathbb{D},{ }^{2}\right.$ Guo-An Wang, ${ }^{1}$ Gang-Wei Li, ${ }^{3}$ and Feng-Shuo Li ${ }^{1}$ \\ ${ }^{1}$ School of Transportation Engineering, Jiangsu Vocational Institute of Architectural Technology, Xuzhou 221116, Jiangsu, China \\ ${ }^{2}$ Science \& Technology Innovation Center, Coal Mining and Designing Department, Tiandi Science \& Technology Co., Ltd., \\ Beijing 100013, China \\ ${ }^{3}$ State Key Laboratory of Mining Response and Disaster Prevention and Control in Deep Coal Mines, \\ Anhui University of Science and Technology, Huainan 232001, Anhui, China \\ Correspondence should be addressed to Zeng-Qiang Yang; zengqiang5@126.com
}

Received 19 December 2020; Revised 3 January 2021; Accepted 7 January 2021; Published 23 January 2021

Academic Editor: Guangchao Zhang

Copyright (c) 2021 Zeng-Qiang Yang et al. This is an open access article distributed under the Creative Commons Attribution License, which permits unrestricted use, distribution, and reproduction in any medium, provided the original work is properly cited.

In order to study the occurrence mechanism of advanced coal pillar instability failure and support crushing accidents during a long-wall face passing across abandoned roadways period, the Panel LW3101 in Shenghua Colliery was taken as a typical engineering background. By means of in situ investigation, physical simulation experiment, theoretical analysis, in situ tests, and relevant monitoring methods, the occurrence mechanism and prevention measures are studied. The results show that the bearing stress in advanced coal pillar is accumulated larger and larger with the width of advanced coal pillar gradually decreasing, and meanwhile, the key stratum in overlying strata would also be sliding instability under some minimum critical width condition; the sudden failure of advanced coal pillar which leads to a sharp increase of bending moment is the key factor that induces fracture of the main roof in front of long-wall face, and the advanced fracture of the main roof can be prevented by changing the stress state of the advanced coal pillar from a two-dimensional state to a three-dimensional state; the method of backfilling abandoned roadway is used to improve the stability of advanced coal pillar and the corresponding monitoring results verify that this method is effective. The research conclusions provide a theoretical foundation and new guidance for preventing advanced coal pillar instability failure and support crushing accidents under a long-wall face passing across abandoned roadways condition.

\section{Introduction}

In recent years, with the integration of China's coal resources, many small coal mines that belong to towns and individuals have been consolidated. As the coal seams in these small coal mines have been mined before, and there are many abandoned roadways left in the coal seams. During the new coal mines mining after consolidation, the mining face will pass across abandoned roadways in the mining process. When a mining face passes across an abandoned roadway, how to sustain the surrounding rock stability of the mining face and the abandoned roadway is the key factor $[1,2]$. As the mining face advances toward an abandoned roadway, the width of the advanced coal pillar between them decreases gradually, but the bearing stress on the advanced coal pillar increases gradually, and then it is easy to induce advanced coal pillar instability failure and supports crushing accidents.

Oyler et al. [3] summarized more than 130 cases of mine pressure accidents during mining activities period, and two typical failure mechanisms of roadways were summarized as follows: one was that roof caving accidents caused by instability failure of immediate roof, and the other was that roof periodic weighting accidents caused by instability failure of main roof; Xu et al. [4] established the mechanical model of main roof above abandoned roadways and then revealed the stability mechanism of main roof above 
abandoned roadways; Liu et al. [5] analyzed the mine pressure behaviors under different mining stages, such as before passing across an abandoned roadway, passing across an abandoned roadway, and after passing across an abandoned roadway, and then the corresponding mechanisms of roof fracture were analyzed and summarized; Li et al. [6] analyzed the apparent characteristics of mine pressure in passing across abandoned roadways period and concluded that the size of advanced coal pillar, the size of abandoned roadway, and the strength of bearing medium were the main factors that affect the stress distribution of working face; Liu et al. [2] studied the whole process of a long-wall face that advanced across several abandoned roadways, and the failure mechanism of main roof was analyzed in detail, and the corresponding reinforcement support mechanism was put forward at the same time; Cheng et al. [7] studied the physical and mechanical properties of a new kind of filling material and analyzed the mechanical property of advanced coal pillar after backfilling by filling material in abandoned roadways.

Many scholars have a certain amount of researches about failure mechanisms of advanced coal pillars, and a series of corresponding countermeasures are also proposed. These scholars have also studied the relationship between support technology and overburden activity laws from the perspective of roadway support design and field practice, and then the feasible prevention and control measures were proposed [8-11]. However, the experimental study on the evolution of overburden fracture characteristics and the experimental study on the evolution of overburden structural stability in such mining conditions were less studied. Especially for this kind of mining conditions, the advanced fracture of the main roof and its subsequent slide instability were not studied in detail. Therefore, in this paper, the physical simulation experiment method is used to analyze the process of a long-wall face passing across abandoned roadways, and the corresponding advanced fracture mechanism of the main roof is studied in detail based on the results of the physical simulation experiment. Subsequently, based on the elastic foundation beam theory, the relative relation of advanced coal pillar' width and abandoned roadway' width is studied in detail, and then the different backfilled methods for an abandoned roadway are studied in terms of difference value of vertical stress and horizontal stress. The study conclusions can provide a theoretical foundation and new guidance for preventing accidents during a long-wall face passing across the abandoned roadways period.

\section{General Situation of Geology}

2.1. Mining and Engineering Geological Conditions. The present analysis is based on the relationship of Panel LW3101 and abandoned roadways in Shenghua Colliery, Shanxi Province, China. The production capacity of this colliery is approved as $30 \mathrm{Mt}$ per year, and the main mineable coal seam is No. 3. As coal seam No. 3 is about $6.5 \mathrm{~m}$ in average thickness and the direct mining height is about $2.2 \mathrm{~m}$. Therefore the fullmechanized caving mining method is used in long-wall faces of the whole colliery. The average buried depth and the width of panel LW3101 are about $210 \mathrm{~m}$ and $84 \mathrm{~m}$, respectively, and it belongs to a long-wall mining technology in the shallow coal seam. Because coal seam No. 3 has been mined by illegal small colliery before, and there are several abandoned roadways left in coal seam No. 3. When the panel LW3101 was mined, it was found that there were several abandoned roadways across this panel were in front of it. The spatial positional relation of panel LW3101 and abandoned roadways are shown in Figure 1.

2.2. In Situ Investigation. Several abandoned roadways were found during the panel LW3101 mining period, and these abandoned roadways were severely deformed or even impassable as they had been abandoned for a long time. The in situ investigation photos are shown in Figure 2.

It can be seen from Figure 2(a) that the typical abandoned roadway (I) was found during the driving period, and the entrance of this abandoned roadway was in good condition. There was not coal and rock mass piled up at the entrance of this abandoned roadway, which means that when the panel LW3101 was advanced, the distance between the long-wall face and abandoned roadway can be easily identified. It can be seen from Figure 2(b) that the typical abandoned roadway (II) was not easy to find during the driving period, and the entrance of this abandoned roadway was in poor condition. There was coal and rock mass piled up at the entrance of this abandoned roadway, which means that when the panel LW3101 was advanced, the distance between the long-wall face and abandoned roadway could not be easily identified. For example, as there was an abandoned roadway not identified in time, and when the longwall face advanced near to this abandoned roadway, the advanced coal pillar could not bear the higher bearing stress, and it loses stability instantly. A serious accident occurred when the distance between the long-wall face and abandoned roadway was about $12 \mathrm{~m}$, accompanied by advanced coal pillar instability failure. The in situ investigation photos and schematic diagram of this serious accident are shown in Figure 3.

According to Figure 3(c), it can be seen that the bearing stress in advanced coal pillar is accumulated larger and larger, and meanwhile, the width of the advanced coal pillar is getting smaller and smaller. Finally, the advanced coal pillar will not bear the sharp increase of overburden pressure at some critical width and the overlying rocks will be sliding instability. The sliding instability of overlying rocks will form a strong dynamic load and also apply stress to advanced coal pillars, which will form a high concentrated static load at the same time. The combined dynamic and static loads are the key factor to induce a serious accident, and the damage of hydraulic supports and advanced coal pillar instability failure are both the appearance characteristics of this serious accident.

\section{Physical Simulation Experiment Analysis}

3.1. The Establishment of the Two-Dimensional Model. The actual prototype of a mine is made into a model in accordance with certain scale reduction, and the physicomechanical properties of synthetic materials in this model are similar to the physicomechanical properties of 


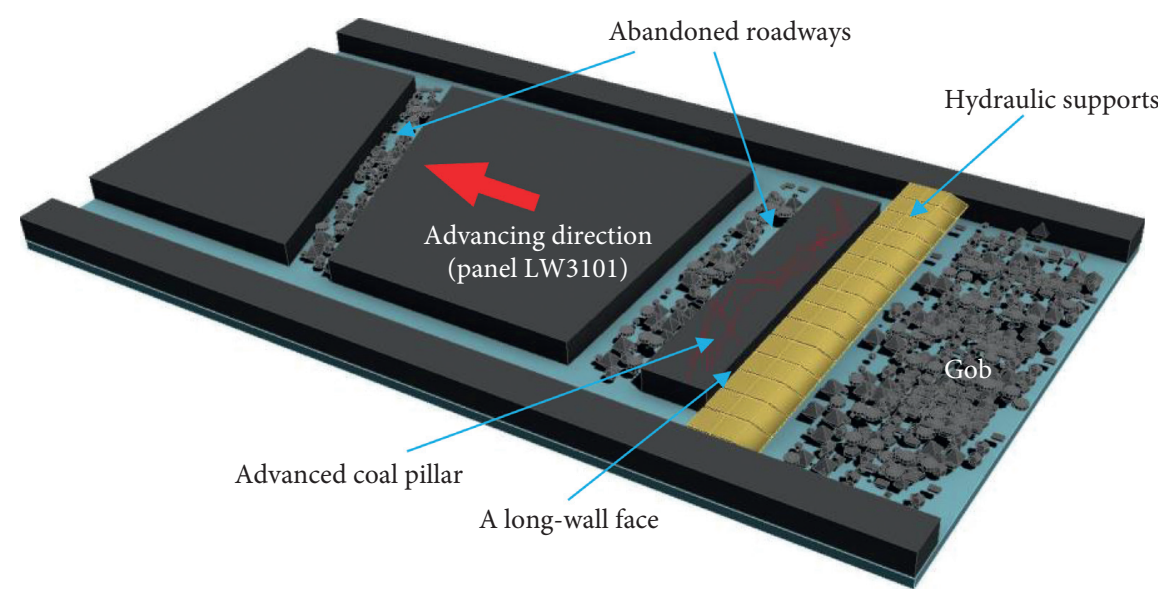

Figure 1: The spatial positional relation of panel LW3101 and abandoned roadways.

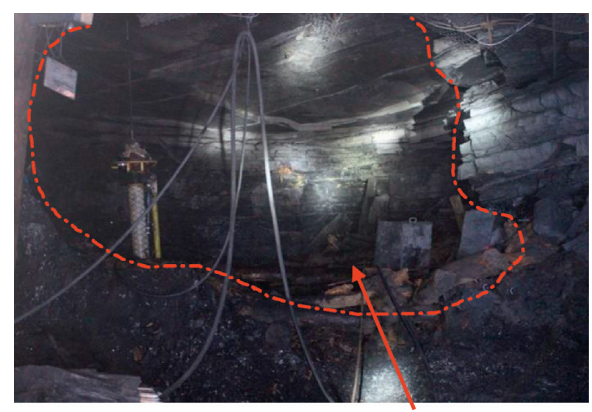

Typical abandoned roadway (I)

(a)

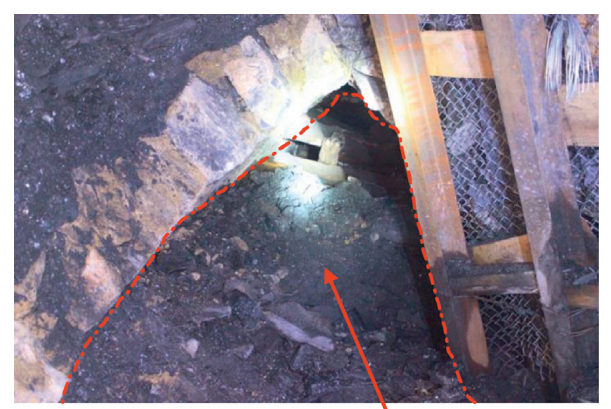

Typical abandoned roadway (II)

(b)

FIGURE 2: The in situ investigation photos for abandoned roadways. (a) Typical abandoned roadway (I); (b) typical abandoned roadway (II).

natural coal-rock mass. The model is used to simulate the actual mining environment, and finally, the deformation, failure, and overlying rock movement laws of this model are observed. Based on the observed results from model driving and mining stages, what happens in actual mining activities can be inferred. The above series of operating processes are called the physical simulation experiment method [12-14]. The physical simulation experiment method is widely used in mining activities, and it is an effective method to analyze the structural characteristics of overlying rocks during the mining period. Therefore, this method is specifically applied to analyze the structural characteristics of overlying rocks during Panel LW3101 mining period. The physicomechanical properties of synthetic materials in this model can be determined by Table 1 .

The two-dimensional model was established on a scale of 1 : 30 , and its specific size was $3.0 \mathrm{~m} \times 2.0 \mathrm{~m} \times 0.2 \mathrm{~m}$ (length $\times$ height $\times$ width). The synthetic materials were made up of sand, calcium carbonate, and gypsum powder under the different ratios, and the different ratios of sand, calcium carbonate, and gypsum powder in synthetic materials were all determined by the corresponding physicomechanical properties of natural coal-rock mass and the mica sheets were used to stratify between different rock layers or coal seam and rock layers. The two-dimensional model is finally established as shown in Figure 4.
Note that $i$ refers to an abandoned roadway with a width of $6.6 \mathrm{~m}$, ii refers to an abandoned roadway with a width of $12.0 \mathrm{~m}$, iii refers to an abandoned roadway with a width of $6.6 \mathrm{~m}$, and ivi refers to an abandoned roadway with a width of $2.2 \mathrm{~m}$.

According to Figure 4(a), it could be seen that four abandoned roadways (i iv) were set up in the two-dimensional model based on mining and engineering geological conditions of Panel LW3101. The widths of four abandoned roadways were $2.2 \mathrm{~m}, 6.6 \mathrm{~m}, 12.0 \mathrm{~m}$, and $6.6 \mathrm{~m}$ in turn along the advancing direction of Panel LW3101, and ten pressure cells $(1 \# \sim 10 \#)$ in the coal seam to monitor the stress evolution law during Panel LW3101 mining period. The pressure cells (as shown in Figure 4(d)) were connected to the pressure dates receiver by some signal lines that went through the back of the model (as shown in Figure 4(b)), and the pressure cells were buried in the coal seam of this twodimensional model during its establishment period. The physical simulation supports (as shown in Figure 4(e)) used in the two-dimensional model were controlled by supports control and resistance dates receiver system (as shown in Figure 4(c)), and the corresponding monitoring dates were fed back to this system. The physical simulation support moved along the advancing direction by a horizontal thrust that was provided by hand during the mining period in this two-dimensional model. 


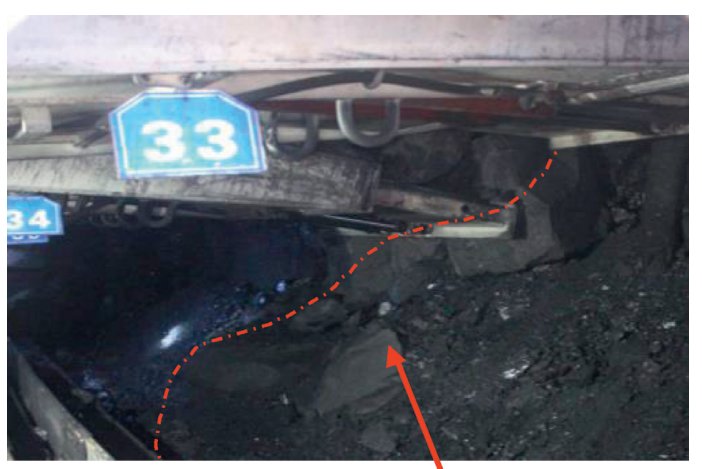

Advanced coal pillar instability failure

(a)

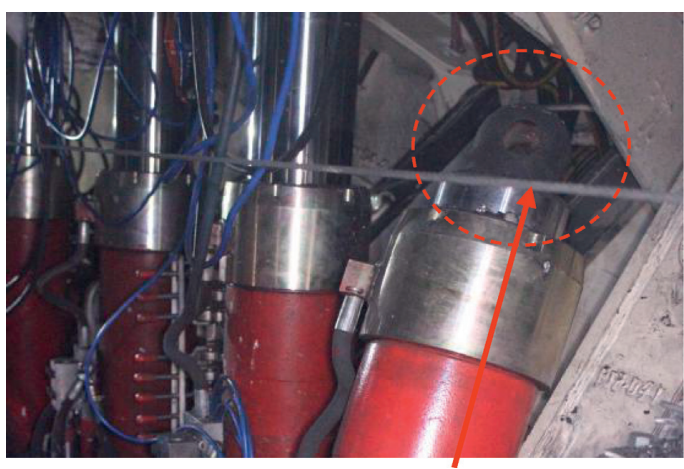

Damage of hydraulic support

(b)

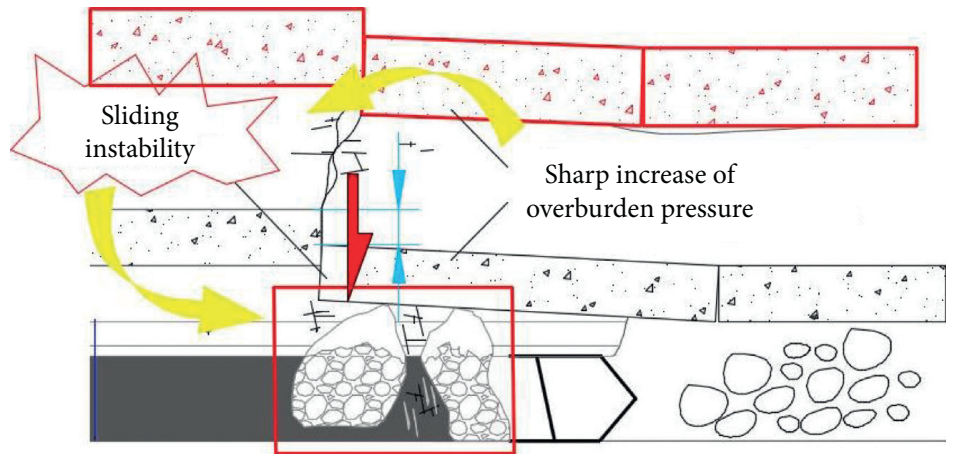

(c)

Figure 3: The in situ investigation photos and schematic diagram of a serious accident. (a) Advanced coal pillar instability failure; (b) damage of hydraulic support; (c) schematic diagram of a serious accident.

TABLE 1: The ratio for different similarity model materials.

\begin{tabular}{lcc}
\hline Name & Strength $(\mathrm{MPa})$ & Ratio number \\
\hline Mudstone & 135 & 373 \\
Fine sandstone & 250 & 537 \\
Siltstone & 200 & 355 \\
Medium sandstone & 280 & 337 \\
Gritstone & 235 & 755 \\
Coal seam & 82 & 573 \\
\hline
\end{tabular}

\subsection{The Analysis of Experimental Results. In the advancing} process of long-wall face in this model, when the long-wall face was advanced near to an abandoned roadway (ii), the advanced coal pillar suddenly became unstable under some minimum critical width condition, and meanwhile, the overlying rocks in overlying strata would also be sliding instability. The advancing processes of long-wall face across to the abandoned roadway (ii) are shown in Figure 5.

It could be seen from Figure 5(a) that when the long-wall face advanced across through the abandoned roadway (iii) and abandoned roadway (iv), the fracture of the main roof in overlying rocks was lagging behind the long-wall face, and the long-wall face was protected by an unbroken cantilever beam. Therefore, the bearing pressure was relatively small in advanced coal pillar and the working resistance of physical simulation supports was only about $5700 \mathrm{kN}$; it could be seen from Figures 5(b) and 5(c) that when the long-wall face advanced across through the abandoned roadway (ii), the advanced coal pillar suddenly became unstable under some minimum critical width condition, and meanwhile, the unbroken cantilever beam in overlying rocks would suddenly break and the fracture position was ahead of the long-wall face. Therefore, the bearing pressure in the advanced coal pillar was relatively large and the working resistance of physical simulation supports suddenly increased to about $12500 \mathrm{kN}$; it could be seen from Figure 5(d) that the voussoir beam structure of the main roof was unable to maintain a stable state with the follow-up advancing processes of long-wall face, and the main roof and the soft layers above it would be sliding instability. At this point, the advanced coal pillar would lose its bearing capacity and the working resistance of physical simulation supports would continue to increase to about $16200 \mathrm{kN}$, and then the supports would be easily damaged.

It can be seen from Figure 6(a) that when an abandoned roadway is far away from the long-wall face, the long-wall face is in a normal advancing stage. The failure position of 


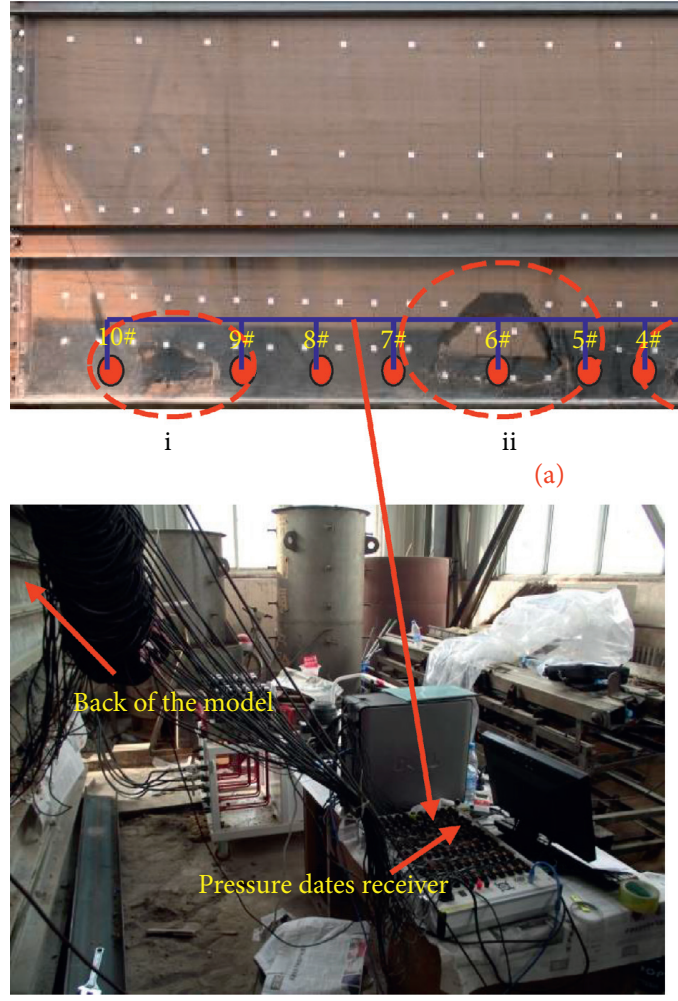

(b)

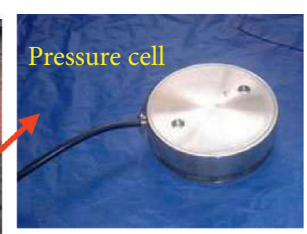

(d)

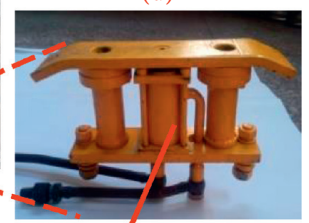

iii

iv

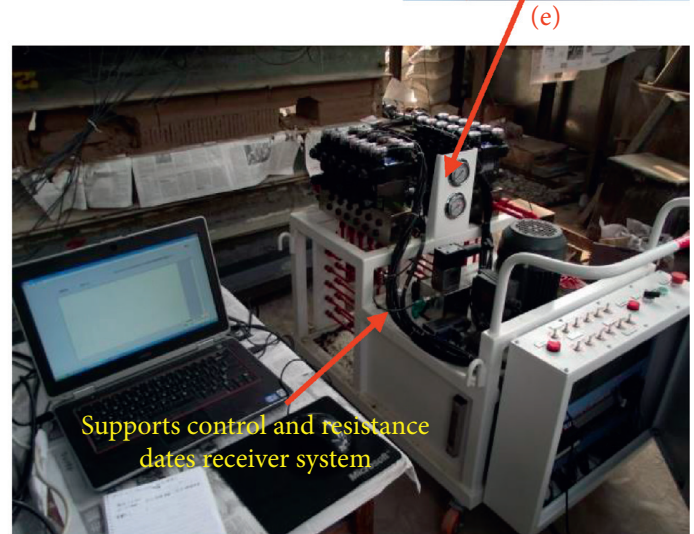

(c)

Figure 4: The in situ investigation photos and schematic diagram of a serious accident. (a) Two-dimensional model; (b) pressure dates receiver; (c) supports control and resistance dates receiver system; (d) pressure cells; (e) physical simulation supports.

the main roof is usually located behind the long-wall face, and the main roof can form half-arch or hinged arch structures when it fails. These structures can bear the overlying rocks load, and then the long-wall face is in a low stress environment. The weak intercalated layers that are controlled by the main roof will break, rotate, and sink with the main roof together, while the inferior key strata above weak intercalated layers usually lags behind the failure of main roof, and then there is an abscission zone between the inferior key strata and weak intercalated layers. Therefore, the weak intercalated layers below the abscission zone can be seen as a loading strata of the main roof, while the inferior key strata above the abscission zone breaks, rotates, and sinks with hysteresis, and then it has no influence on the advancing activities of long-wall face. In addition, according to the critical layer theory [15], the front arch foot of the halfarch or hinged arch structures formed by keyblocks of the main roof is the main bearing point of load, and the physical simulation supports can maintain the stability of the halfarch or hinged arch structures by prevention of its downward sliding trend.

When there is an abandoned roadway in front of the long-wall face, the overlying rocks evolution laws and the stability of half-arch or hinged arch structures will change. Because the width of advanced coal pillars gradually decreases to minimum critical width with the advancing process of long-wall face, the corresponding bearing capacity also gradually decreases to minimum critical bearing load.
At this time, the physical simulation supports are limited by the spatial relationship of the advanced coal pillar, and then the physical simulation supports cannot support the roof of the advanced coal pillar in time. Finally, the failure position of the main roof is located in front of the long-wall face. When the advanced coal pillar suddenly became unstable under minimum critical width condition, the relative stability of half-arch or hinged arch structures in overlying rocks will be broken in an instant and the loading strata will be sliding instability. Then the working resistance of hydraulic supports will increase instantly, and even the hydraulic supports are damaged at representative locations, as shown in Figures 6(b) and 6(c).

\section{Mechanism of the Advanced Fracture and Prevention Measures}

4.1. Bending Moment in Overlying Rocks. The analysis of experimental results in Section 3.2 shows that the advanced fracture of the main roof is the key factor to induce damaged accident of supports. However, which factor induces the advanced fracture and how to avoid it are still unknown. It is a well-known fact that the maximum bending moment usually induces a fracture in the main roof. Therefore, the fracture position of the main roof can be judged by the maximum bending moment. Above all, the elastic foundation beam theory $[16,17]$ is used to do any further calculations, and the coal seam and advanced coal pillar can be seen as the foundations. 

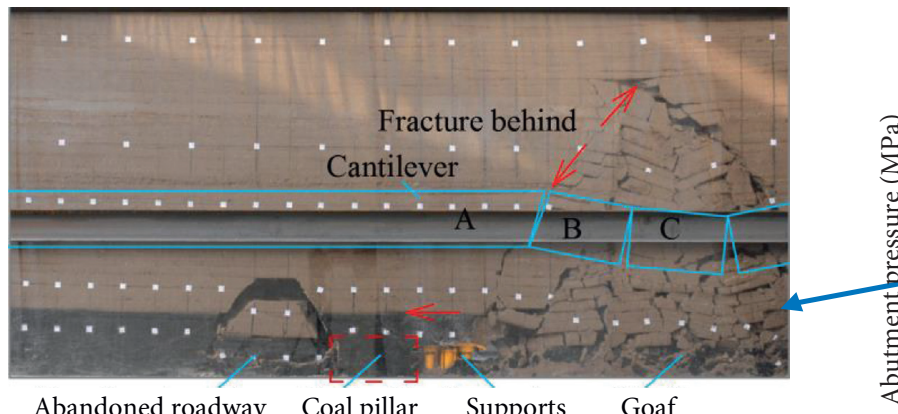

(a)

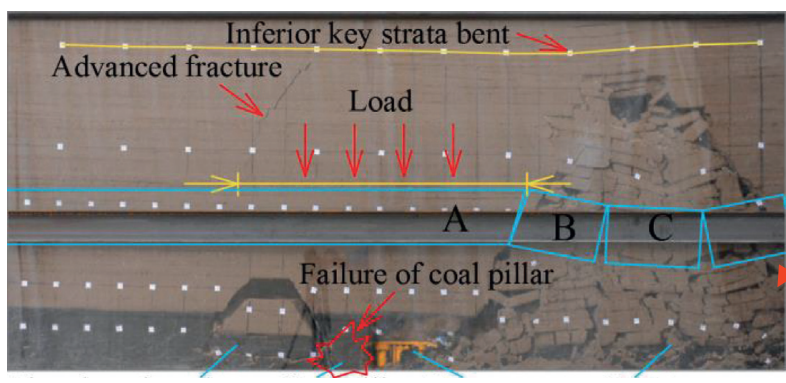

Abandoned roadway Coal pillar Supports Goaf

(b)

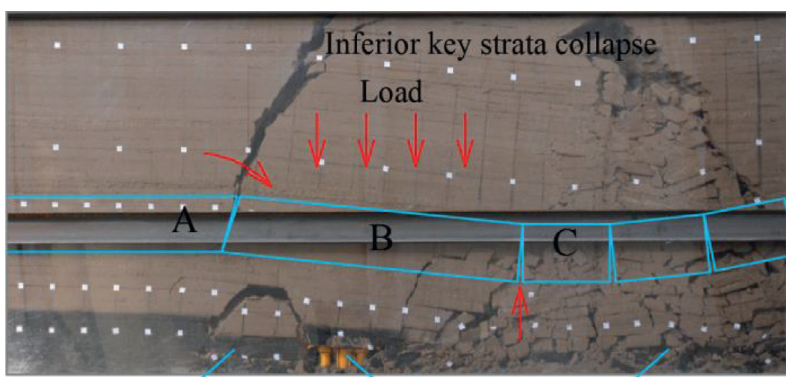

Abandoned roadway

Supports

Goaf

(c)

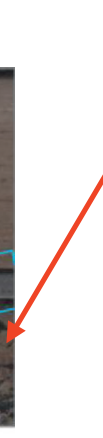

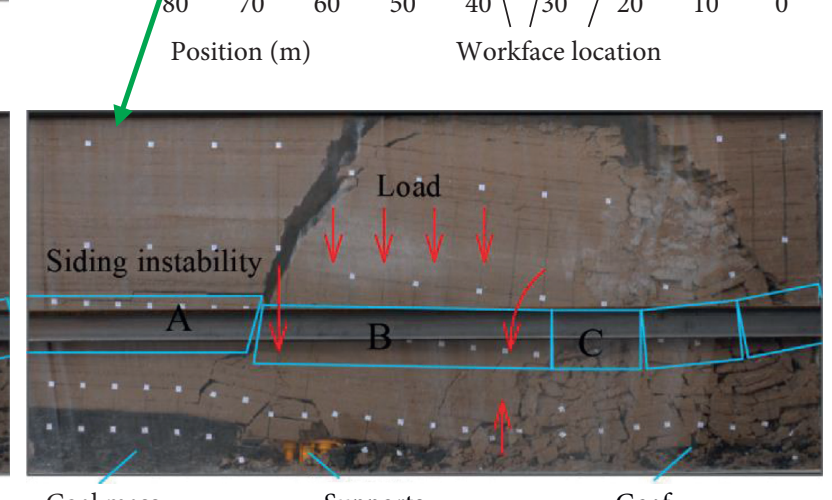

Coal mass

Supports

Goaf

(d)

FIgURE 5: The advancing processes of long-wall face across to abandoned roadway (ii). (a) At the position of $23 \mathrm{~m}$, (b) at the position of $31 \mathrm{~m}$, (c) at the position of $35 \mathrm{~m},(\mathrm{~d})$ at the position of $39 \mathrm{~m}$, (e) abutment pressure curves, and (f) working resistance curves.

Figure 7 shows the complete stress-strain curve of the coal sample from Panel LW3101. The coal sample keeps being compressed in the pre-failure region and loses stability once it exceeds the limit. Advanced coal pillar also has the same mechanical properties. With Panel LW3101 mining, the load on advanced coal pillars increases gradually. The increasing pressure will cause a large deformation of advanced coal pillar and then a corresponding large deflection of the main roof. Finally, the main roof will fracture. In order to reveal the evolution laws of the bending moment in this period, both the bending moment in prefailure region (zone I in Figure 7) or in postfailure region (zone II in Figure 7) should be studied.

Firstly, the coal seam and advanced coal pillar should be assumed to meet the Winkler foundation model, as shown in the following:

$$
p=-k \cdot y
$$

where $p$ is the vertical bearing stress of foundation to the main roof; is the vertical displacement of the foundation; $y$ is the foundation modulus, and the value is $1 \times 10^{2} \mathrm{MPa}$.

What should be noted is that when the advanced coal pillar is destabilized and destroyed, its width is viewed as $0 \mathrm{~m}$, as shown in Figure 8 (zone II: $W=0$ ).

Figure 9 shows the stress conditions and boundary conditions of the main roof.

In this mechanical model, the main roof is seen as a cantilever beam. The differential equation of bending deformation can be got according to the Timoshenko solution [18]:

$$
\begin{aligned}
& E I y^{\prime \prime \prime \prime}+N y^{\prime \prime}=q-k y, \quad(0 \leq x \leq W), \\
& E I y^{\prime \prime \prime \prime}+N y^{\prime \prime}=q, \quad\left(W \leq x \leq W+W_{a}\right), \\
& E I y^{\prime \prime \prime \prime}+N y^{\prime \prime}=q-k y, \quad\left(W+W_{a} \leq x<\infty\right),
\end{aligned}
$$




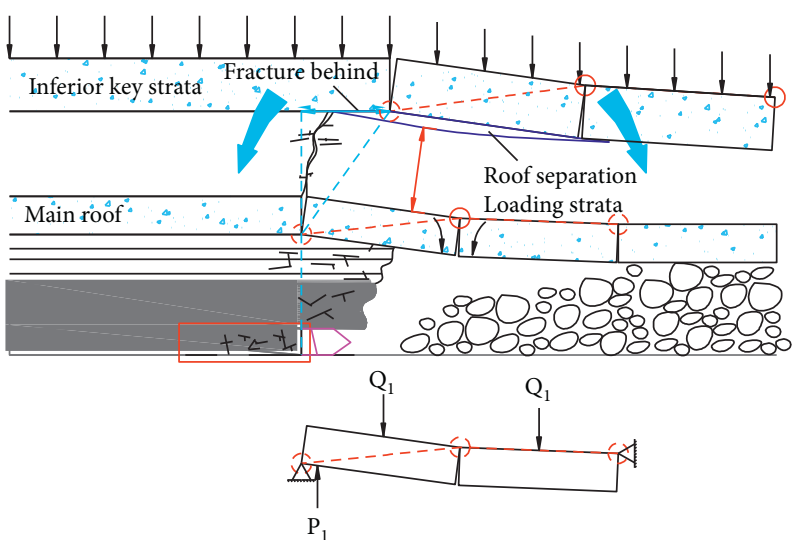

(a)

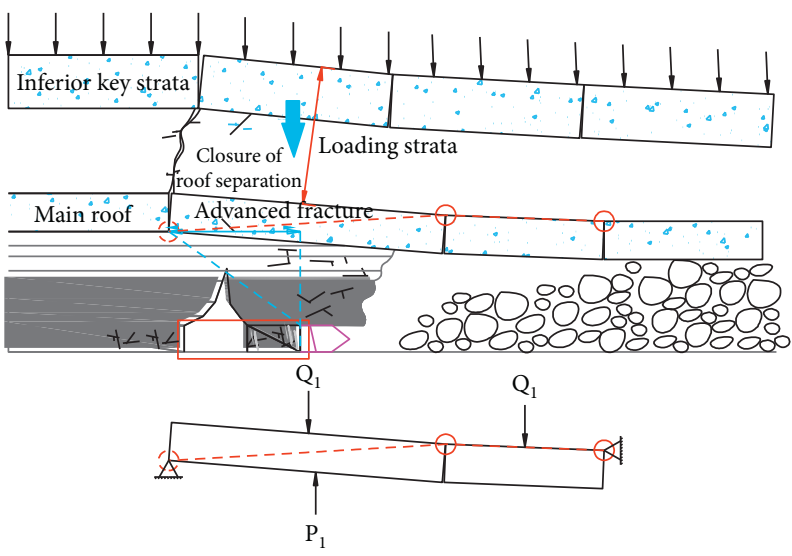

(b)

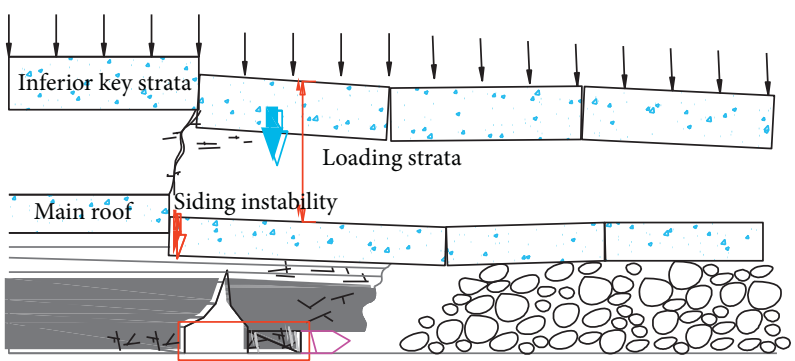

(c)

FiguRE 6: The overlying rocks evolution laws of long-wall face across to abandoned roadway. (a) Normal advancing stage, (b) abnormal advancing stage (before siding instability), and (c) abnormal advancing stage (after siding instability).

where $E$ is the elasticity modulus of the main roof; $I$ is the moment of inertia of the main roof; $W$ is the width of advanced coal pillar; $W_{a}$ is the width of the abandoned roadway.
According to the relevant literature, the general solution can be deduced by simultaneous equations of (2)-(4), as follows:

$$
y(x)=\frac{1}{2} e^{\alpha x}[(A+C) \cos \beta x+(B+D) \sin \beta x]+\frac{1}{2} e^{-\alpha x}[(A-C) \cos \beta x+(B-D) \sin \beta x]
$$

where $\alpha=(\sqrt{(k / E I) / 2})-(N / E I)$ and $\beta=(\sqrt{(k / E I) / 2})-$ $(N / E I)$.

It can be seen from equation (5) that there are four coefficients that cannot be determined, and they are $A, B, C$, and $D$, respectively.

When $x$ goes to infinity, the monomial expression of $e^{a x}$ is equal to 0 . Thus the following relationship can be obtained:

$$
\begin{aligned}
& A+C=0, \\
& B+D=0 .
\end{aligned}
$$

Then, the general solutions of equation (4) are as follows: $y_{3}(x)=e^{-\alpha x}\left(A_{3} \cos \beta x+B_{3} \sin \beta x\right)+C_{3}, \quad\left(W+W_{a} \leq x<\infty\right)$.

It is easy to know that $A_{3}, B_{3}$, and $C_{3}$ are algebraic about $M_{W+W_{a}}$ and $Q_{W+W_{a}}$, which is the bending moment and shear force at $x=W+W_{a}$, respectively. In consideration of the continuity of equations 2 and (3) at $x=W+W_{a}$ and $x=W$, then the general solutions of equations (2) and (3) are as follows:

$$
\begin{aligned}
& y_{1}(x)=e^{-\alpha x}\left(A_{1} \cos \beta x+B_{1} \sin \beta x\right)+e^{\alpha x}\left(D_{1} \cos \beta x+E_{1} \sin \beta x\right)+C_{1}, \quad(0 \leq x<W), \\
& y_{2}(x)=A_{2} \cos \beta_{0} x+B_{2} \sin \beta_{0} x+C_{2}+D_{2} x+E_{2} x, \quad\left(W \leq x \leq W+W_{a}\right) .
\end{aligned}
$$


As the bending moment and shear force at $x=W+W_{a}$ and $x=W$ should be continuous, thus, the only unknown parameters are $M_{0}, Q_{0}$, and $N$. According to the equilibrium conditions and the voussoir beam theory $[19,20], M_{0}, Q_{0}$, and $N$ are given as follows:

$$
\begin{aligned}
M_{0} & =E I y_{0}^{\prime \prime}=\frac{1}{2} q L^{2}+Q^{\prime} L+N \frac{H}{2}, \\
Q_{0} & =E I y_{0}^{\prime \prime \prime}+N y_{0}^{\prime}=q L+Q^{\prime}, \\
N & =\frac{L Q^{\prime}}{2(H-s)}, \\
Q^{\prime} & =L \gamma H, \\
s & =\frac{H}{6},
\end{aligned}
$$

where $q$ is the load intensity of the main roof, and $q=\gamma\left(H+H^{\prime}\right) ; H$ is the thickness of the main roof, and $H=4 \mathrm{~m} ; H^{\prime}$ is the thickness of the load stratum, and $H^{\prime}=2 \mathrm{~m}$; $\gamma$ is the unit weight of overlying strata, and $\gamma=25 \mathrm{kN} / \mathrm{m}^{3} ; E I$ is the flexural rigidity of the main roof, and $E=30 \mathrm{GPa}$, $I=5.33 \mathrm{~m}^{4} ; \sigma_{s}$ is the strength of extension of the main roof, and $\sigma_{s}=6 \mathrm{MPa} ; L$ is the max-length of the above-mentioned beam in the main roof, and $L=7.62 \mathrm{~m}$; and $M_{0}$ and $Q_{0}$ are the bending moment and the shearing force at $x=0$.

Based on the above conditions, the deflection and the bending moment of the main roof under 3 kinds of widths of roadways $\left(W_{a}\right)$ and 4 kinds of widths of advanced coal pillars $(W)$ were calculated and the calculation results were shown in Figure 8.

(1) According to Figures $8(\mathrm{a})$ and $8(\mathrm{~b})$, with the increasing of roadway width $\left(W_{a}=0 \mathrm{~m}\right.$ to $W_{a}=2 \mathrm{~m}$ to $W_{a}=5 \mathrm{~m}$ to $W_{a}=10 \mathrm{~m}$ ), the deflection of the main roof increases, the max bending moment in main roof decreases and moves to long-wall face except for the case of $W_{a}=2 \mathrm{~m}$ and $W=2 \mathrm{~m}$.

(2) According to Figure 8(e), the deflection leads to a compression of the supports and the advanced coal pillar which can well correspond with the increase of working resistance and transfer forward of bearing pressure.

(3) Despite the case of $W_{a}=2$ and $W=2$, once the advanced coal pillar assumes to never been instability, the peak of bending moment moves to the long-wall face with the roadway's width increasing, like a knife cutting the overlying rocks. Abnormal fracture will not take place. Therefore, the key to prevent an abnormal fracture of overlying rocks is to ensure the stability of advanced coal pillar.

(4) As to the case of $W_{a}=2$ and $W=2$, the max bending moment increases and reverses to the long-wall face. Thus, it is hard to avoid an advanced fracture when moving into a narrow roadway. Fortunately, the advanced distance $(2.8 \mathrm{~m})$ is not too large when comparing with the mining height of the coal seam $(2.2 \mathrm{~m})$.

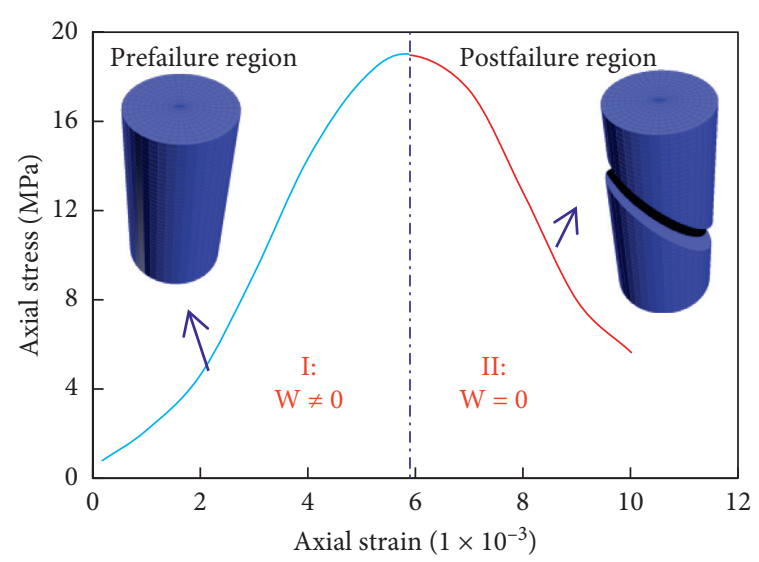

Figure 7: The complete stress-strain curve of the coal sample.

(5) Figures $8(d)-8(f)$ have another form of the data in Figures $8(\mathrm{a})-8(\mathrm{c})$, and they have the same variation with the coal pillar mining. It should be noted that once the width of the advanced coal pillar is reduced to $0 \mathrm{~m}(W=0 \mathrm{~m}$ in Figure $8(\mathrm{c})$ or Figures $8(\mathrm{~d})-8(\mathrm{f}))$, the bending moment and the deflection of the main roof increase sharply. The sharply increased bending moment may lead to a sudden fracture of the main roof which is far ahead of the long-wall face.

Above all, it can be seen that the sudden failure of advanced coal pillar which leads to a sharp increase of bending moment which is the key factor that induces fracture of the main roof ahead of long-wall face. If the stability of the advanced coal pillar can be well maintained, the corresponding advanced fracture can be prevented.

\subsection{Factors Discussion on Maximum Bending Moment.} Figure 10 shows sensibility of the peak of bending moment and its distance to the mining face with $W_{a}$ and $W$ changes. It can be seen that the changes of $W_{a}$ and $W$ induce little changes of the peak of bending moment and its distance to the long-wall face when advanced coal pillar is assumed to be not instability. However, the peak and the distance increase sharply when the width of the advanced coal pillar approximates to $0 \mathrm{~m}$, which means the advanced coal pillar has been instable. Thus, more attention should be paid to the advanced coal pillar's failure and measures should be taken to maintain the advanced coal pillar's stability when referring to the advanced fracture.

4.3. Factors Discussion on Abnormal Fracture. The above sections discussed the change in the width of the advanced coal pillar and its corresponding effects on the maximum bending moment. However, whether the bending moment reaches the limit and leads to a fracture also depends on the hanging length of the main roof. It is well known that abnormal fracture always takes place in a periodic weighting period. There are 3 kinds of relative position relation between the abandoned roadway and periodic fracture position in the main roof, as shown in Figure 11. Base on this, the actual hanging length of the main roof after the advanced coal pillar's failure is easy to get. 

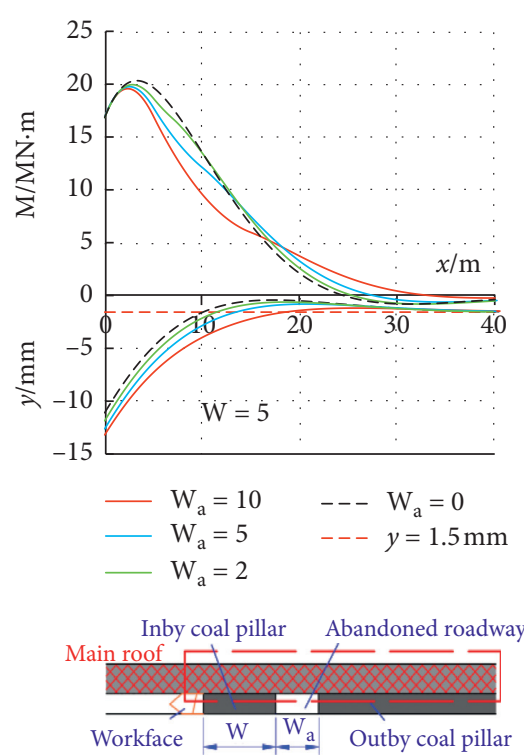

(a)

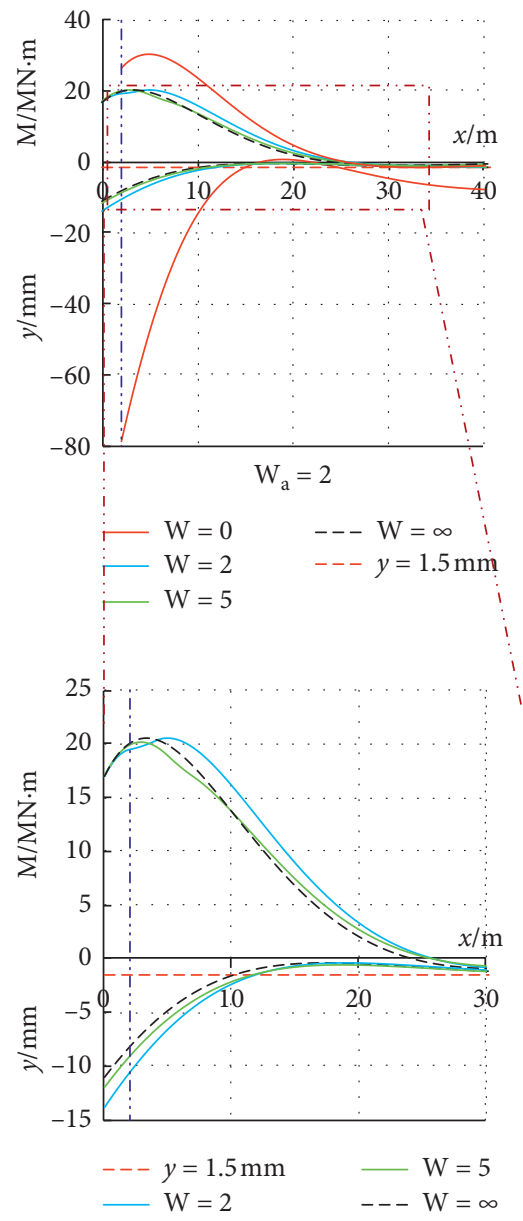

(d)

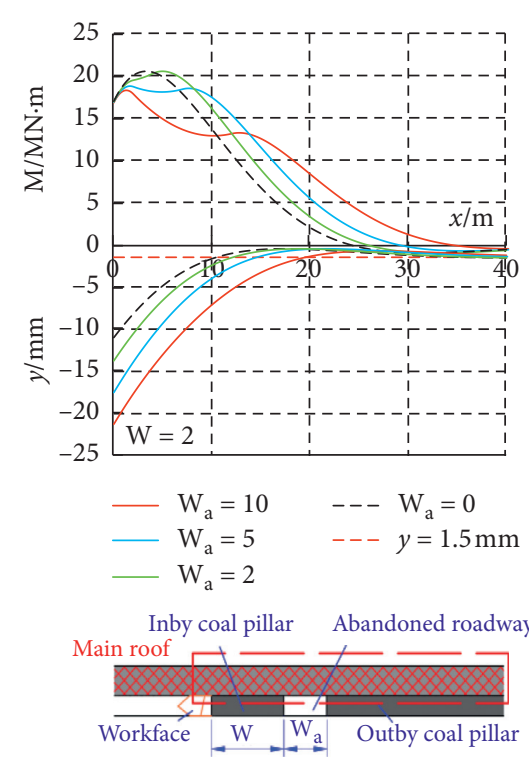

(b)
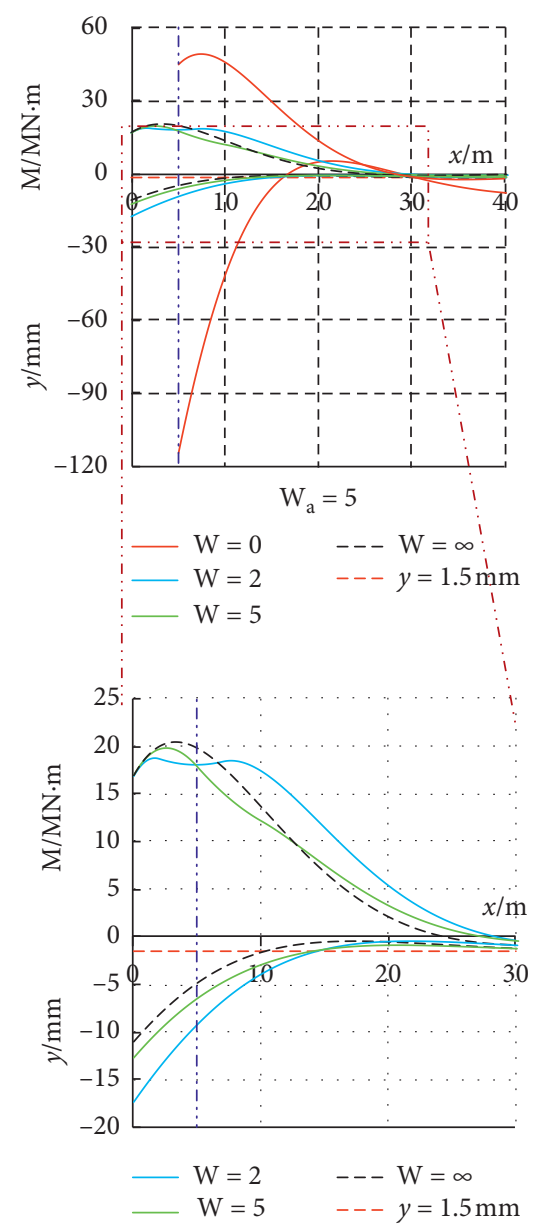

(e)

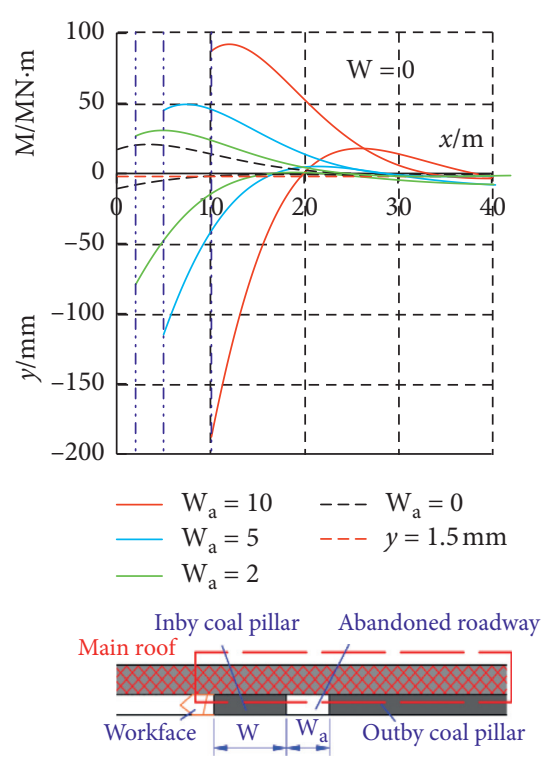

(c)
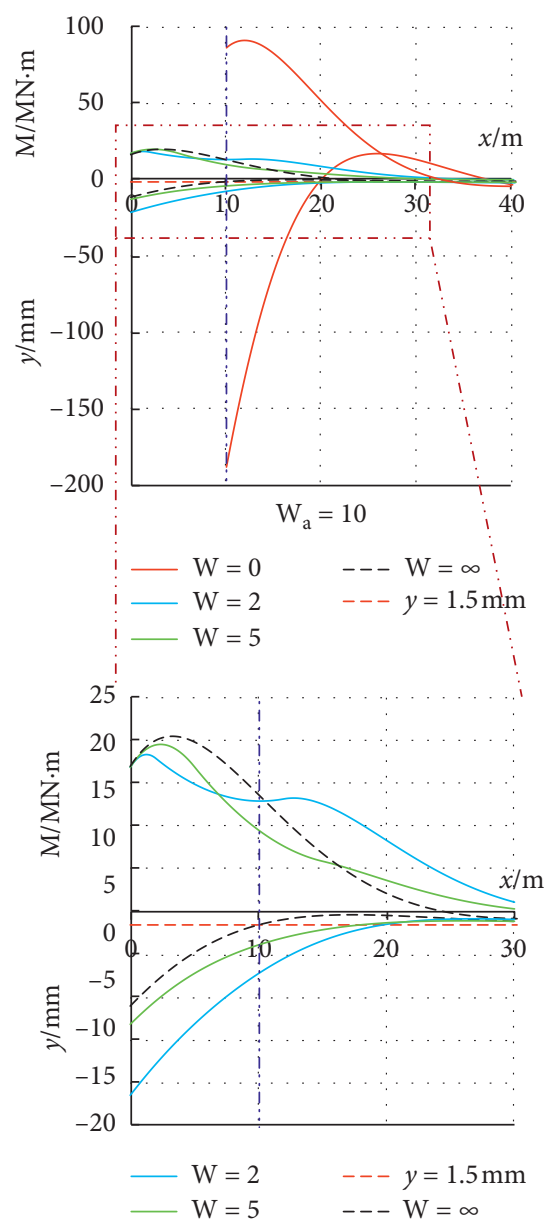

(f)

FIGURE 8: Evolution laws of bending moment and vertical deflection in the main roof. (a) Bending moment $(W=5 \mathrm{~m})$, (b) bending moment $(W=2 \mathrm{~m}),(\mathrm{c})$ bending moment $(W=0 \mathrm{~m}),(\mathrm{d})$ vertical deflection $\left(W_{a}=2 \mathrm{~m}\right)$, (e) vertical deflection $\left(W_{a}=5 \mathrm{~m}\right)$, and (f) vertical deflection $\left(W_{a}=10 \mathrm{~m}\right)$. 


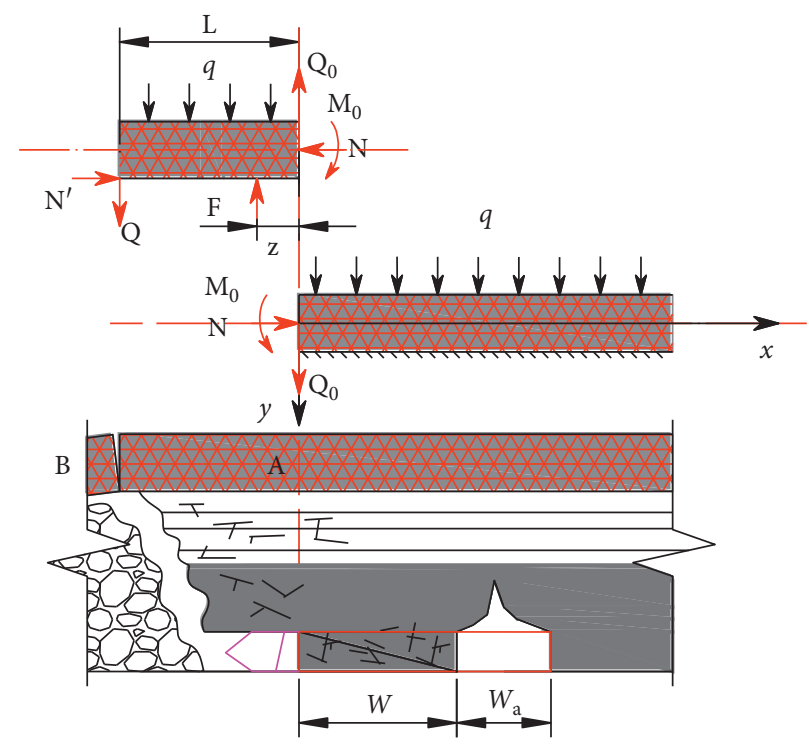

FIGURE 9: The mechanical model of the main roof.

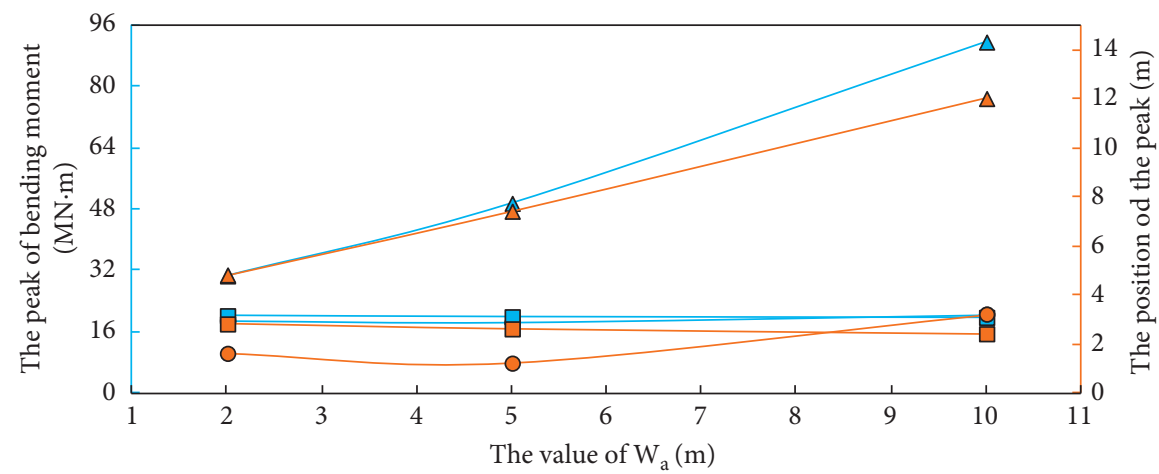
$-\mathrm{O}-\mathrm{W}=5$
$-\mathrm{O}-\mathrm{W}=5$
$\square-W=2$
$\square-W=2$
$\triangle W=0$
$\triangle W=0$

(a)

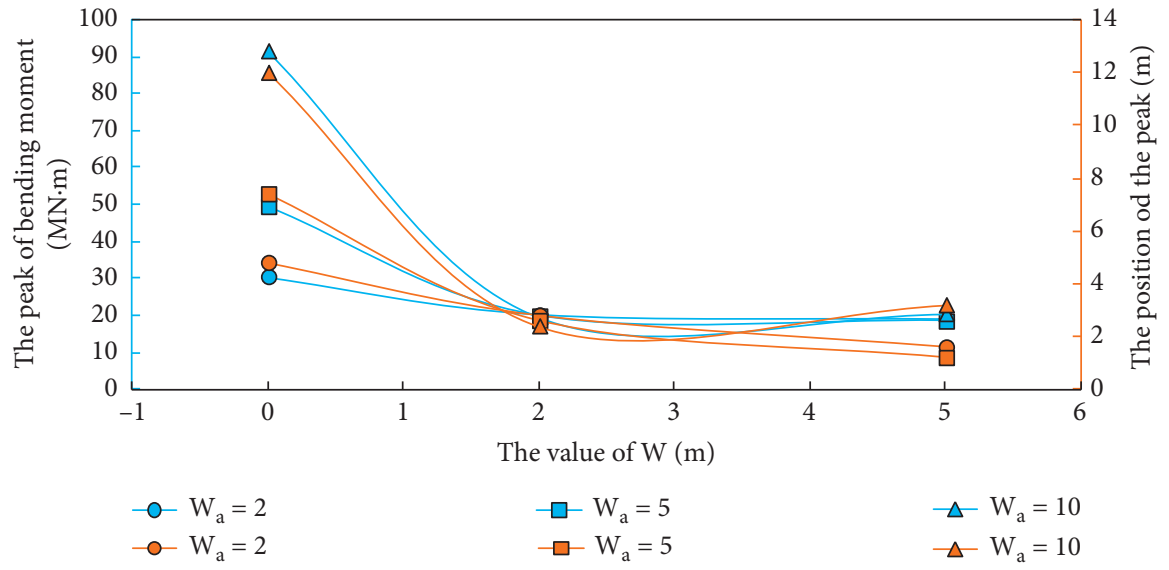

(b)

FIGURE 10: Sensibility factors analysis of the peak of bending moment. (a) Different values of $W_{a}$; (b) different values of $W$. 


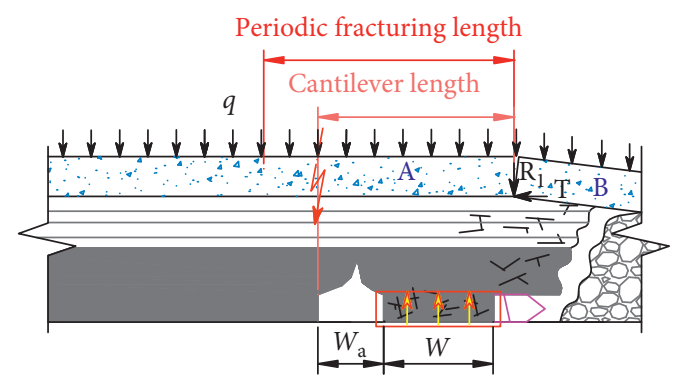

(a)

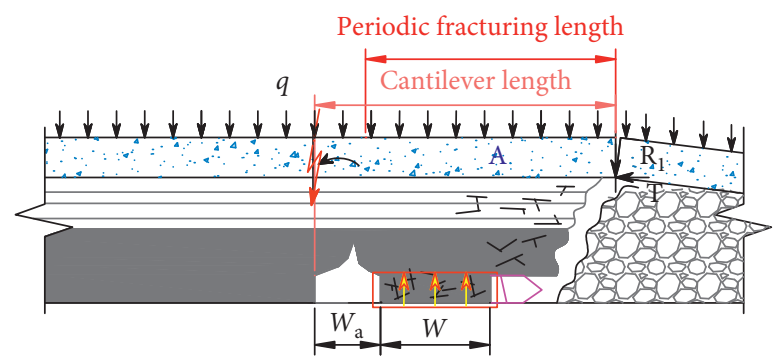

(b)

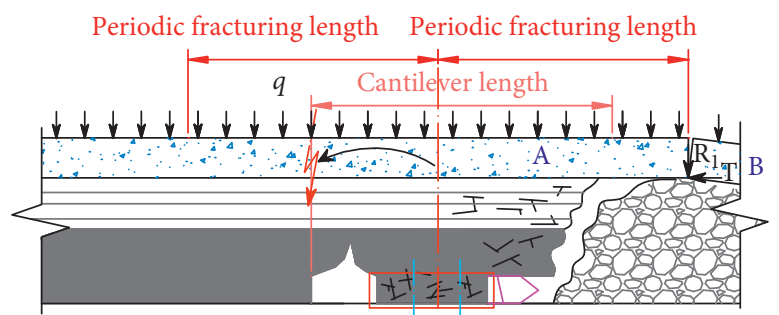

(2) (1)

(c)

FIGURE 11: The relative position relation between the abandoned roadway and fracture position. (a) Fracture of the main roof (type i); (b) fracture of the main roof (type ii); (c) fracture of the main roof (type iii).

According to Figure 11, the last main roof periodic weighing has finished and the next main roof periodic weighing has not happened. Whether the abnormal fracture takes place can be illustrated as follows:

(1) According to Figure 11(a), it can be seen that when the cumulative width of the abandoned roadway and advanced coal pillar is less than the periodic weighing length of the main roof, and the cantilever length of the main roof is also less than the periodic weighing length of the main roof, even if the advanced coal pillar has been destabilized and destroyed, the main roof will not suffer the abnormal fracture.

(2) According to Figure 11(b), it can be seen that when the cumulative width of the abandoned roadway and advanced coal pillar is larger than the periodic weighing length of the main roof, and the cantilever length of the main roof is also larger than the periodic weighing length of the main roof, and the fracture line of next main roof periodic weighing is located above the abandoned roadway, once the advanced coal pillar has been destabilized and destroyed, the main roof will suffer the abnormal fracture.

(3) According to Figure 11(c), when the fracture line of the next main roof periodic weighing is located above the advanced coal pillar, and then the cantilever length of the main roof is larger than the periodic weighing length of the main roof. In this case, when the advanced coal pillar is destabilized and destroyed in zone (1), the main roof will suffer an abnormal fracture, and when the advanced coal pillar is destabilized and destroyed in zone (2), the main roof will not suffer the abnormal fracture.

4.4. Analysis of Prevention Method. The above sections show that the relative relation of advanced coal pillar' width and abandoned roadway' width is the main factor to induce advanced coal pillar instability failure and supports crushing accidents. Therefore, how to improve the stability of advanced coal pillar becomes the main method to prevent and control accidents. The method of backfilling abandoned roadway is used to prevent and control accidents [21, 22], as shown in Figure 12.

It can be seen from Figure 12 that when the abandoned roadway is backfilled by different methods, such as timber cribs, hydraulic props, and filling material, which will provide correspondingly different horizontal stresses $\left(\sigma_{3}\right)$. Especially when the abandoned roadway is backfilled by filling materials, the filling materials will provide greater horizontal stress, and then the difference value of vertical stress $\left(\sigma_{1}\right)$ and horizontal stresses $\left(\sigma_{3}\right)$ is changed. According to Figure 12(b), which was obtained from laboratory test results, it can be seen that the larger the horizontal stresses $\left(\sigma_{3}\right)$ is, the more stable the advanced coal pillar is, and the advanced coal pillar can bear larger vertical stress $\left(\sigma_{1}\right)$ at this time. The filling materials and advanced coal pillar can be seen as integration, and then the stress state of the advanced coal pillar goes from a twodimensional state to a three-dimensional state. The advanced coal pillar will be regarded as part of the coal seam, and the subsequent mining can be seen as conventional mining activities. Then the advanced coal pillar will never lose its stability. 

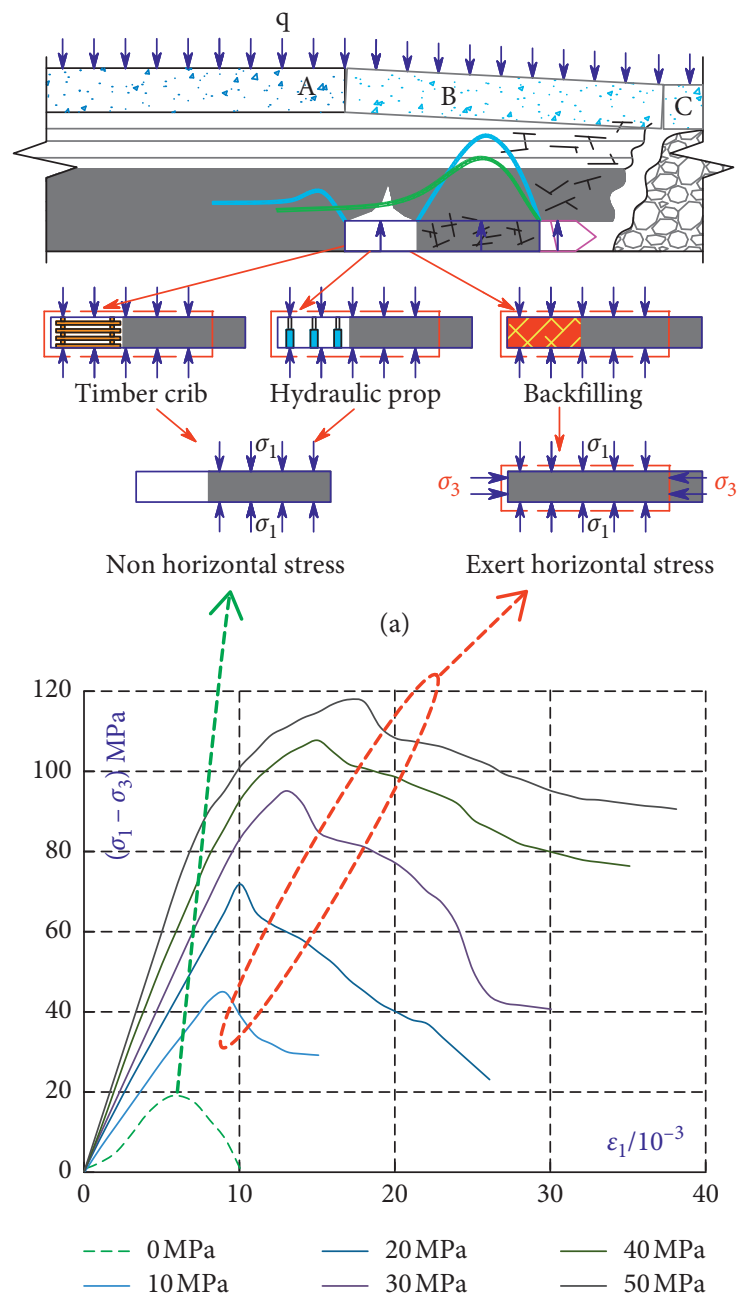

(b)

FIGURE 12: The analysis of the backfilling mechanism of the abandoned roadway. (a) Mechanical model; (b) stress-strain curves.

\section{Field Industrial Tests}

During the follow-up mining period of Panel LW3101, there are still several abandoned roadways in front of the long-wall face. The method of backfilling abandoned roadway is applied to these abandoned roadways, as shown in Figure 13.

It can be seen from Figure 13(a) that when the advanced coal pillar instability failure and supports crushing accidents have already happened, and the rest of the abandoned roadways are treated by a backfilling method. When an abandoned roadway was backfilled by filling material, which was used by slurry A and slurry B in a ratio of $1: 1$, it could be seen from Figure 13(a) that the filling body was composed of two parts from bottom to top. The low part was a soft layer which was a mixture of woods, gangues, coal blocks, and low-strength cementing body. The middle part was a hard layer that was composed of a high-strength cementing body. The filling body did not need to fill the entire abandoned roadway completely, and the height of the filling body only needed to be high enough to maintain the stability of the advanced coal pillar and prevent gangues from rolling into the long-wall face. The top part of the filling body was composed of falling rocks.
Considering the engineering geological conditions on site, the length of the filling body along the driving direction of abandoned roadways could not cover the whole roadway, and then the length of safe operation was about $25 \mathrm{~m}$. This means that there was a length of $25 \mathrm{~m}$ filling body could provide horizontal stress to maintain the stability of the advanced coal pillar, and then the length of long-wall face across the abandoned roadways would decrease.

Figures 13(b) and 13(c) were the borehole peep photos of filling body in abandoned roadways, which were obtained by a sighting instrument $[23,24]$, and the backfilling effect could be judged by these photos. Figure 13(d) showed that the entrance of this abandoned roadway was also backfilled by a filling body, and the reinforcement measures were carried out at the same time. Figures 13(e) and 13(f) showed that the stability extent of advanced coal pillars after backfilling was very good during the follow-up mining period of Panel LW3101. Figure 13(g) showed that the work resistance change laws of hydraulic supports which were monitored during the follow-up mining period of Panel LW3101, and the monitoring results showed that the maximum work resistance of hydraulic supports was less than $3000 \mathrm{kN}$ and the periodic weighing length of the main 


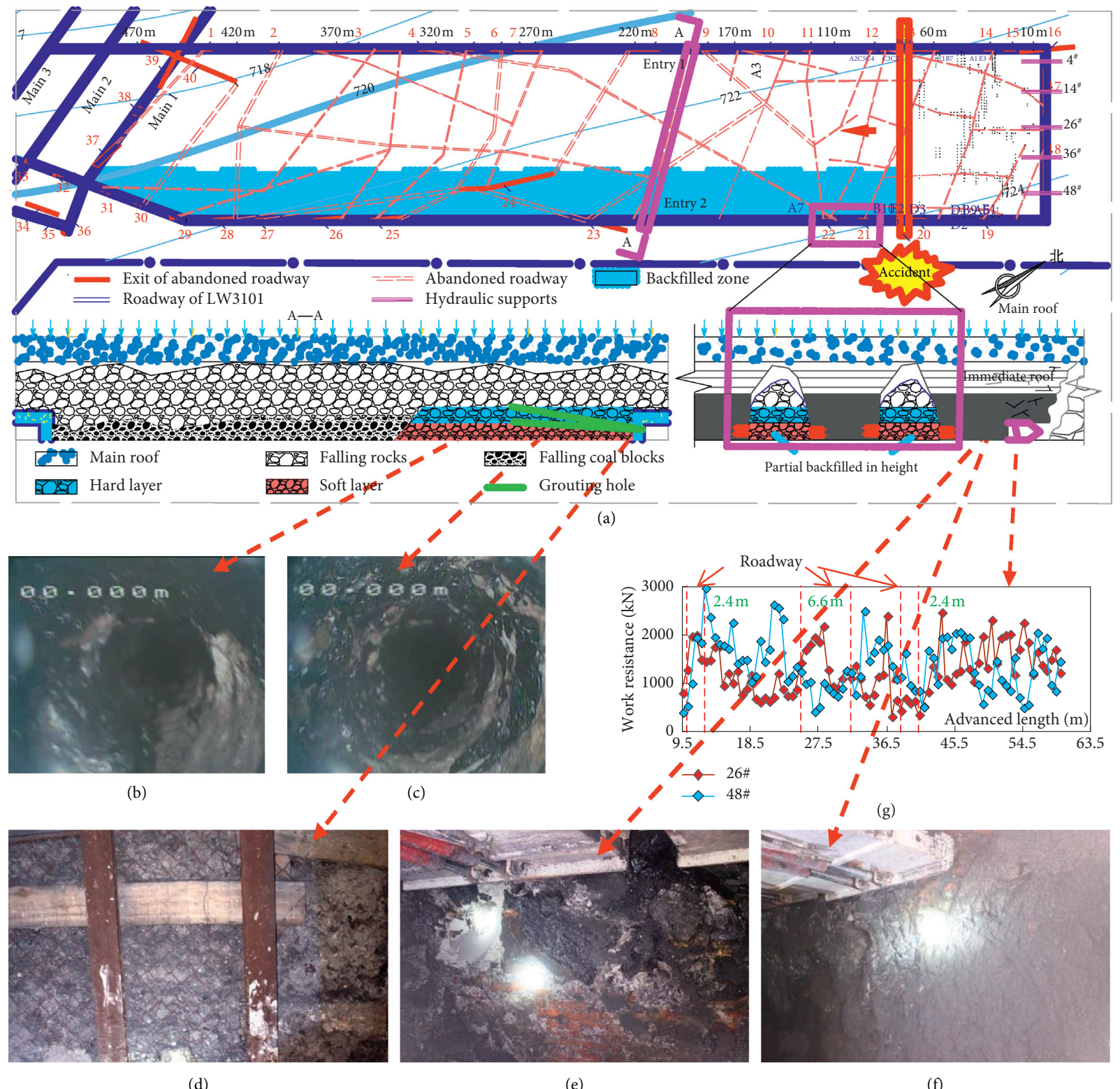

(d)

(e)

(f)

FIGURE 13: The method of backfilling abandoned roadway on Panel LW3101. (a) Backfilling method, (b) borehole peep photos i, (c) borehole peep photos (ii), (d) photo about the entrance of this abandoned roadway, (e) photo about mining face i, (f) photo about mining face (ii), and $(\mathrm{g})$ work resistance.

roof was about $10.2-11.6 \mathrm{~m}$, which mean that the main roof would not suffer the abnormal fracture and the advanced coal pillar would never lose its stability.

\section{Conclusions}

(1) When a long-wall face passes across an abandoned roadway, the sliding instability of overlying rocks will form a strong dynamic load and also apply stress to advanced coal pillar which will form a high concentrated static load at the same time. The combined dynamic and static loads are the key factor to induce the accidents of advanced coal pillar instability failure and supports crushing.
(2) When there is an abandoned roadway in front of the long-wall face, the overlying rocks evolution laws and the stability of half-arch or hinged arch structures will change. As the hydraulic supports are limited by the spatial relationship of advanced coal pillars, the relative stability of half-arch or hinged arch structures in overlying rocks will be broken in an instant and the loading strata will be sliding instability. Then the hydraulic supports are vulnerable to damage at representative locations.

(3) The sudden failure of advanced coal pillar which leads to a sharp increase of bending moment is the key factor that induces the main roof's breaking ahead of long-wall face. If the stability of the 
advanced coal pillar could be well maintained, the advanced fracture can be prevented.

(4) The relative relation of advanced coal pillar' width and abandoned roadway' width is the main factor to induce advanced coal pillar instability failure and supports crushing accidents, and then the method of backfilling abandoned roadway is used to improve the stability of advanced coal pillar. The filling materials and advanced coal pillar can be seen as integration, and then the stress state of the advanced coal pillar goes from a two-dimensional state to a three-dimensional state.

(5) The field industrial tests show that the filling body does not need to fill the entire abandoned roadway completely, and the height of the filling body only needs to be high enough to maintain the stability of the advanced coal pillar and prevent gangues rolling into long-wall face. The work resistance change laws of hydraulic supports which are monitored during the follow-up mining period of Panel LW3101 and the monitoring results show that the main roof will not suffer an abnormal fracture and the advanced coal pillar will never lose its stability.

\section{Data Availability}

All data used to support the findings of this study are included within the article, and there are not any restrictions on data access.

\section{Conflicts of Interest}

The authors declare no conflicts of interest.

\section{Acknowledgments}

The work was supported by the Key Project of National Natural Science Foundation of China (No. 51634001) and the National Natural Science Foundation of China (Nos. 51574243, 51404269, and 51674253).

\section{References}

[1] C. Liu, Z. Yang, P. Gong et al., "Accident analysis in relation to main roof structure when longwall face advances toward a roadway: a case study," Advances in Civil Engineering, vol. 2018, Article ID 3810315, 11 pages, 2018.

[2] C. Liu, Z. Q. Yang, P. L. Gong et al., "Mechanism and control technology of supports crushing induced by main roofs breaking ahead of workface when crossing abandoned roadway," Journal of China Coal Society, vol. 42, no. 8, pp. 1932-1940, 2017.

[3] D. C. Oyler, C. Mark, D. R. Dolinar, and R. C. Frith, "A study of the ground control effects of mining longwall faces into open or backfilled entries," Geotechnical and Geological Engineering, vol. 19, no. 2, pp. 137-168, 2001.

[4] Q. Y. Xu, Z. X. Ning, R. S. Zhu et al., "Study on instability mechanism and top control of overfilled roof in fully mechanized caving face," Journal of Mining \& Safety Engineering, vol. 36, no. 3, pp. 505-512, 2019.
[5] J. Y. Liu and G. B. Kang, "Laws of strata behaviors of 12413 working face passing through overlying empty lane in Bailianta coal mine," Safety in Coal Mines, vol. 49, no. S1, pp. 18-26, 2018.

[6] H. T. Li, Y. X. Zhao, Y. D. Jiang et al., "Strata behavior and principal controlling factors analysis of working face under upper-stratified coal pillar group," Safety in Coal Mines, vol. 45, no. 6, pp. 192-195, 2014.

[7] J. Cheng, W. F. Li, P. Zhang et al., "A novel backfill material for roof supports in the cut-through entries of longwall mining," Tehnicki Vjesnik-Technical Gazette, vol. 22, no. 1, pp. 201-208, 2015.

[8] Z. Yang, L. Dou, C. Liu, M. Xu, Z. Lei, and Y. Yao, "Application of high-pressure water jet technology and the theory of rock burst control in roadway," International Journal of Mining Science and Technology, vol. 26, no. 5, pp. 929-935, 2016.

[9] J. N. Wu, X. W. Feng, B. K. Liu et al., "Rapid removing technology of heavy fully mechanized top coal caving mining face without preset removing gateway," Coal Science and Technology, vol. 36, no. 5, pp. 14-17, 2008.

[10] S. C. Gu, B. N. Wang, R. B. Huang et al., "Method for determining the load on and width of coal pillar at the recovery room end of fully-mechanized longwall mining," Journal of China University of Mining \& Technology, vol. 44, no. 6, pp. 990-995, 2015.

[11] C. Liu, P. L. Gong, and K. Wang, "Roof stability for repeated mining workface passing through abandoned parallel gateway," Journal of China Coal Society, vol. 40, no. 2, pp. 314-322, 2015.

[12] M. G. Qian, P. W. Shi, and J. L. Xu, Mining Pressure and Strata Control, pp. 30-55, China University of Mining and Technology Press, Xuzhou, China, 2010.

[13] X. R. Jia, Rock Mechanics and Rock Strata Control, pp. 130155, China University of Mining and Technology Press, Xuzhou, China, 2010.

[14] J. Ju and J. Xu, "Structural characteristics of key strata and strata behaviour of a fully mechanized longwall face with $7.0 \mathrm{~m}$ height chocks," International Journal of Rock Mechanics and Mining Sciences, vol. 58, no. 1, pp. 46-54, 2013.

[15] Q. X. Huang, Roof Structure and Roof Control Theory of Long Wall Mining in Shallow Seam, pp. 10-45, China University of Mining and Technology Press, Xuzhou, China, 2000.

[16] M. Wang, J. J. Ma, S. J. Han et al., " $1 / 2$ sub-harmonic resonance of beams on Winker foundation with consideration of finite-depth soil motion," Journal of Vibration and Shock, vol. 39, no. 11, pp. 165-170, 2020.

[17] J. J. Ma, Z. G. Qin, F. J. Liu et al., "Free vibration of beams on winkler foundation with the consideration of finite-depth soil motion," Journal of Vibration and Shock, vol. 38, no. 6, pp. 62-66, 2019.

[18] Y. Y. Fu and Y. Y. Yu, "Analytical solution to transverse free vibration characteristics of a simply supported Timoshenko beam on viscoelastic Pasternak foundation," Journal of Vibration and Shock, vol. 39, no. 19, pp. 32-38, 2020.

[19] J. G. Guo, W. G. Wang, Z. Q. Yang et al., "Research of coal pillar inducing rock burst in L-shaped zone of working face and prevention technology," Journal of Mining Science and Technology, vol. 2, no. 1, pp. 49-57, 2017.

[20] L. M. Dou and X. Q. He, Theory and Technology of Rock Burst Prevention, pp. 40-65, China University of Mining and Technology Press, Xuzhou, China, 2001.

[21] G. C. Zhang, L. J. Chen, Z. J. Wen et al., "Squeezing failure behavior of roof-coal masses in a gob-side entry driven under 
unstable overlying strata," Energy Science \& Engineering, vol. 8, no. 1, pp. 1-14, 2020.

[22] Z. Zhang, J. Bai, Y. Chen, and S. Yan, "An innovative approach for gob-side entry retaining in highly gassy fullymechanized longwall top-coal caving," International Journal of Rock Mechanics and Mining Sciences, vol. 80, pp. 1-11, 2015.

[23] G. C. Zhang and F. L. He, "Asymmetric failure and control measures of large cross-section entry roof with strong mining disturbance and fully-mechanized caving mining," Chinese Journal of Rock Mechanics and Engineering, vol. 35, no. 4, pp. 806-818, 2016.

[24] Z. Z. Zhang, M. Deng, J. B. Bai et al., "Strain energy evolution and conversion under triaxial unloading confining pressure tests due to gob-side entry retained," International Journal of Rock Mechanics and Mining Sciences, vol. 126, pp. 1-10, 2020. 